WP 41_13

\author{
Sofronis Clerides \\ University of Cyprus, Cyprus \\ Centre for Economic Policy Research (CEPR), UK \\ The Rimini Centre for Economic Analysis (RCEA), Italy \\ Peter Davis \\ Compass Lexecon, UK
}

Antonis Michis

Central Bank of Cyprus, Cyprus

\title{
NATiOnAl SENTIMENT AND CONSUMER CHOICE: THE IRAQ WAR AND SAleS OF US Products in Arab Countries
}

\begin{abstract}
Copyright belongs to the author. Small sections of the text, not exceeding three paragraphs, can be used provided proper acknowledgement is given.
\end{abstract}

The Rimini Centre for Economic Analysis (RCEA) was established in March 2007. RCEA is a private, nonprofit organization dedicated to independent research in Applied and Theoretical Economics and related fields. RCEA organizes seminars and workshops, sponsors a general interest journal The Review of Economic Analysis, and organizes a biennial conference: The Rimini Conference in Economics and Finance (RCEF) . The RCEA has a Canadian branch: The Rimini Centre for Economic Analysis in Canada (RCEACanada). Scientific work contributed by the RCEA Scholars is published in the RCEA Working Papers and Professional Report series.

The views expressed in this paper are those of the authors. No responsibility for them should be attributed to the Rimini Centre for Economic Analysis. 


\title{
National Sentiment and Consumer Choice: The Iraq War and Sales of US Products in Arab Countries*
}

\author{
Sofronis Clerides ${ }^{\dagger}$ \\ Peter Davis ${ }^{\ddagger}$ \\ Antonis Michis ${ }^{\S}$
}

September 2012

\begin{abstract}
Did the rise in anti-American sentiment caused by the Iraq war affect sales of US goods abroad? We address this question using data on soft drink and fabric detergent sales in nine Arab countries. We find a statistically significant negative impact of the war on sales of US soft drinks in seven countries. The impact dissipates after a few months in two countries but persists in the other five. In the case of detergents we only find a significant negative impact in one country. We conclude that international politics can sometimes affect consumer behavior and impact market outcomes.
\end{abstract}

Keywords: consumer choice, consumer boycotts, Iraq war.

JEL Classification: D12, D01, L66.

\footnotetext{
${ }^{*}$ We thank Iacovos Avraamides for research assistance, the Nielsen company for providing the data used in this study, and Alon Eizenberg for useful comments. The views expressed in this paper are solely the views of the authors acting in a personal capacity and are, in particular, in no way reviewed or endorsed by any of the institutions for which the authors work.

Correspondence: Sofronis Clerides, Department of Economics, University of Cyprus, P.O.Box 20537, CY-1678 Nicosia, Cyprus. Phone: +357 2289 3709; fax: +357 22895049.

${ }^{\dagger}$ University of Cyprus and CEPR; s.clerides@ucy.ac.cy.

${ }^{\ddagger}$ Compass Lexecon; pdavis@compasslexecon.com.

${ }^{\S}$ Central Bank of Cyprus; AntonisMichis@centralbank.gov.cy.
} 


\section{Introduction}

The US-led war in Iraq dominated the international political scene from the fall of 2002 to the summer of 2003 and remained in the headlines for several years thereafter. The acrimonious debate over the war's military, legal and ethical justification led to a straining of relations between erstwhile close allies, particularly the United States and France. French objections over the necessity of war led to a rise in anti-French sentiment in the United States. American displeasure toward the French manifested itself in a variety of ways, perhaps most famously in the renaming of french fries as "freedom fries". Less symbolic but potentially more harmful reactions included campaigns calling for boycotts of French products. The effectiveness of these campaigns has been a subject of debate in recent economic research, with one study reporting an estimated drop of $10-12 \%$ in bilateral trade between the US and France. ${ }^{1}$

Most directly however, the Iraq war raised anti-US sentiment in many parts of the world, particularly among Arabs. Surveys conducted in six Arab countries (Morocco, Saudi Arabia, Jordan, Lebanon, UAE, Egypt) show that the percentage of Arabs who had an unfavorable opinion of the US increased from 74 to 84 percent between March 2002 and June 2004 (Zogby International, 2004). This average masks considerable variation across countries, with a staggering $98 \%$ of Egyptians reporting an unfavorable opinion of the US in 2004, up from $76 \%$ in 2002. In contrast, citizens of the United Arab Emirates (UAE) show an improved view of the US over this period (from $87 \%$ unfavorable in 2002 to $73 \%$ in 2004). When respondents in the survey are asked to name the principal factors determining their attitudes towards the US, they overwhelmingly cite the Iraq war, along with US policy towards the Palestinians.

In this paper we provide some evidence on the extent to which the rise of anti-US sentiment due to the invasion of Iraq affected the sales of US goods in Arab countries. Boycott campaigns against US products are reported to have been organized in many Arab countries during this period. The campaigns typically targeted iconic American brands such as McDonald's and

\footnotetext{
${ }^{1}$ Michaels and Zhi (2010). We discuss this literature in more detail in the next section.
} 
Coca-Cola but also extended to products that are less symbolic of America, such as cleaning supplies and electronics. Our study focuses on two product categories, soft drinks and laundry detergents. The soft drink category was chosen as the primary focus of our analysis because it includes Coca-Cola and Pepsi, flagship American brands that may be most vulnerable to a boycott campaign relying on anti-American sentiment. In the laundry detergent category the major US producer is Procter \& Gamble (P\&G), with Colgate having a smaller presence. These companies are probably less high profile as US producers than Coca-Cola or Pepsi. Studying detergents is nonetheless instructive because US producers in this industry face competition from at least two major European manufacturers in each country. The presence of high quality alternatives makes participation in a boycott more likely. ${ }^{2}$ On the other hand, limited availability of substitutes does not rule out the possibility of a successful boycott as long as entry is possible. Indeed, the soft drink category saw a number of new entrants, some of which actively invoked anti-US sentiment during their entry to the market. A prominent example is Mecca Cola, whose senior executive's stated aim was to give the number one US corporation and the Bush administration a "bloody nose". ${ }^{3}$

We first explore the link between public opinion and market outcomes by combining survey evidence on Arab attitudes toward the US with our data on soft drink and laundry detergent sales in Arab countries. A simple regression of the market share of US products in a country on the level of favorable attitudes toward the United States indicates a positive correlation between the two in the soft drink market but not in the detergent market. Though certainly not definitive, this finding suggests that further exploration of this issue with more detailed data in the context of the Iraq war may produce some interesting results.

Using our product-level data, we test for the impact of the Iraq war using a difference-in-

\footnotetext{
${ }^{2}$ The cost to consumers of participating in a boycott depends on the availability of close substitutes. The easier it is to substitute to a similar product, the smaller the cost, and the higher the probability of a successful boycott campaign. See Friedman (1999) and Baron (2003).

3 "We wanted to give a bloody nose directly to the number one corporation [Coca-Cola] that represents corporate America because corporate America represents Bush and Bush represents neo-conservatism." (Rashad Yaqoob quoted in The Independent (London, England); Nov. 26, 2003.)
} 
difference approach that compares the evolution of sales of US products and non-US products during the period before and after the start of hostilities. We find that sales of US soft drinks experienced absolute declines around the time of the Iraq war in every country, with the extent of the decline varying substantially across countries. In seven of the nine countries in our data (Egypt, Jordan, Kuwait, Oman, Qatar, Saudi-Arabia and UAE) we find a statistically significant relative drop in sales of US products - compared to sales of non-US products. The other two countries in our sample (Bahrain and Lebanon) also report economically significant declines in the relative performance of US brands, but the effect is not statistically significant. The basic pattern is clear and robust. The performance of US products dropped significantly before the commencement of combat operations and the effect persisted for the rest of the sample in all countries in our study except Kuwait, where the effects on sales volumes appear markedly more modest. ${ }^{4}$ Analysis of distribution patterns suggests that disruptions in distribution networks may have been at least partially responsible for the decline in American soft drinks sales.

In contrast to soft drinks, we find very little evidence of a decline in the case of US detergent sales. In fact, in several countries, US products actually do better than their non-US counterparts. The pattern of divergent sales paths that was observed in almost all countries in the case of soft drinks is only visible in Egypt and Kuwait and is statistically significant only in the latter. Similarly, the trends in prices and distribution do not exhibit a pattern that can be traced to the political climate.

The results from the analysis at both the aggregate cross-country level and the micro level suggest that perceptions of firms and countries that are shaped by international political developments can and do affect consumer behavior. In this particular case, the Iraq war had a negative effect on the sales of some American firms, notably those selling iconic US products

\footnotetext{
${ }^{4}$ In an earlier version of this paper we did not find long-lived effects. The reason will be explained further below, but essentially occurs because we examined changes in sales only during the three months before and after the commencement of combat operations. As we will see below, the big drop off in sales of US products actually first occurs more than three months before combat operations begin - and then persists for the rest of the sample. The result is that little change is observed (to the differential experience of US and non-US products) when we examine only the short period around combat operations.
} 
such as Coca-Cola and Pepsi. US detergents were not similarly impacted despite the existence of close substitutes from European manufacturers, perhaps because fabric detergents exhibit a less emblematic association with America. A different response from distribution networks may be at least part of the explanation for the different impacts across the two product markets. Although our findings are specific to two consumer goods markets, they provide some useful insights into how national sentiment and political considerations might enter consumers' decision making processes.

\section{Background}

Consumer boycotts and their impact on market outcomes have received considerable attention from economists, political scientists and marketing specialists. Baron (2003) defines 'private politics' to be individual or collective action that does not rely on public order (i.e. lawmaking and the courts) through which people attempt to further their interests by imposing their will on others. Efforts by individuals and groups to influence the policies and practices of private firms is one example of such behavior and consumer boycotts are an important tool that is frequently used to that end. Well-known examples include several campaigns against Nike for labor practices in its Asian factories ${ }^{5}$ and against Exxon Mobil for its environmental record. ${ }^{6}$ Boycotts can also involve government, both as targets and as instigators of boycotts. In 2010, several US cities have announced boycotts against the state of Arizona because of its tough new immigration law. ${ }^{7}$

There is a great deal of both policy and academic debate about the effectiveness of boycotts.

\footnotetext{
${ }^{5}$ A web search for "boycott nike" yields dozens of different calls for boycotts. The site http://www.viet.net/ $\sim$ nike/ by Vietnam Labor Watch is a good starting point.

6 "Environmental Groups Launch Exxon Boycott," National Public Radio, July 12, 2005 [http://www.npr. org/templates/story/story.php?storyId=4749052].

7 "In Wake of Immigration Law, Calls for an Economic Boycott of Arizona," The New York Times, April 26, 2010; "L.A. Becomes Largest City To Boycott Arizona," CBS, May 12, 2010 [http://cbs2.com/local/Los . Angeles.City.2.1689109.html].
} 
Economists are generally skeptical because of the free-rider element involved in boycott participation. A consumer may very well prefer that a firm changes a certain practice if this comes at no cost to him, but he may not be willing to participate in a boycott that would limit his choices. There is surprisingly little formal theoretical analysis of boycotts, some recent exceptions being Baron (2001), John and Klein (2003) and Innes (2006). Empirical research is also limited and its findings are "sketchy and inconclusive" (Baron, 2003). Some recent work has focused on the boycott campaign undertaken in the US against French wines as a reaction to French opposition to the Iraq war. Chavis and Leslie (2009) found evidence of a 13\% drop in French wine sales in the US over the six-month period surrounding the beginning of hostilities. They attributed this decline to the boycott campaigns. Ashenfelter, Ciccarella, and Shatz (2007) have disputed this conclusion claiming that the observed decline was part of a general downward trend in the sales of French wines and was unrelated to the Iraq war. In a broader analysis, Michaels and Zhi (2010) find that strained relations between US and France led to a reduction in bilateral trade by a remarkable 10-12\%, with much of the reduction coming from reduced trade in firms' inputs. Our study differs from Michaels and Zhi (2010) in using product level data from several countries and in exploiting the varying degree of association that different products bear with the object of the boycott. In a related case study Hong, Hu, Prieger, and Zhu (2011) use similar methods as ours to find that Chinese boycotts of French products in 2008 led to a 25-33\% drop in sales of French automobiles.

The international aspect of many of these boycott campaigns brings an interesting dimension to the issue. Are boycotts more effective when an element of patriotism is involved? This question is relevant in foreign policy circles, where experts are interested in the economic impact of US foreign policy on the US itself. One particular debate is over the use of sanctions, which some experts consider to be ineffective but also costly to the US economy (Haass, 1997; Rarick, 2007). In one particular study that utilizes a gravity model framework, Hufbauer, Elliott, Cyrus, and Winston (1997) estimate that in 1995 alone the United States lost $\$ 15$ to $\$ 19$ billion worth of exports to countries that were the target of sanctions. In a related study, Fisman and Miguel 
(2007) find that foreign diplomats living in New York City are more likely to break the law (by parking illegally) if they come from a country with negative attitudes toward the US.

It seems plausible that military interventions could have a similar negative impact as sanctions - both types of intervention may be very unpopular with at least some subsets of consumers. There is no question that the Iraq war stirred anti-American sentiments across the globe and particularly in the Arab world. ${ }^{8}$ Numerous boycott campaigns were organized by individuals and civic groups in many Arab countries. Organizers of such campaigns often provided consumers with lists of European and Asian products they could use as substitutes for US products. Language barriers and distance, both physically and in time, make the collection of quantitative evidence about the number and scale of these boycotts difficult. Nonetheless, we were able to obtain an example of the kind of list that circulated in Saudi Arabia. The list includes a wide range of products and services from US providers: personal hygiene and cleaning supplies, food items and restaurants, clothing, electronics, vehicles and furniture. For each product category the list includes the name of the American brands and a list of substitute products that are of European or Asian origin. ${ }^{9}$ Reports of a number of specific boycotts have also appeared in the international press. For example, the UK's The Guardian newspaper published a story on January 8, 2003 naming McDonald's, Burger King, Tide and Ariel detergents, Pampers, Coca-Cola and Pepsi as some of the targets of an Arab boycott. ${ }^{10}$ By March 2004, a Coca-Cola director is reported in the Khaleej Times as saying "Coca-Cola is looking at a double-digit growth despite tough international and regional competition. And we feel this is achievable as we can see signals of favorable market conditions returning with external factors disappearing." ${ }^{11}$ The report claims that "some US companies have reported a drop in sales of between 25 and 40\%" and goes on to argue that "factories in Iran making Zam Zam Cola are struggling to keep up with demand for their sweeter version of Pepsi and Coca-Cola. In the United Arab Emirates, sales

\footnotetext{
${ }^{8}$ Some survey evidence is presented in section 4 .

${ }^{9}$ Our source has asked us not to publish the actual list.

10 "Arab boycott of American consumer goods spreads," The Guardian, January 8, 2003.

${ }^{11}$ Gurtay Kipcak, Public Affairs and Communications Director, Eurasia and Middle East Division of Coca-Cola, cited in "Coca-Cola launches new drink in UAE," Khaleej Times, March 24, 2004.
} 
of the local Star Cola have soared." AME Info, a provider of online business information in and about the Middle East, reported in April 2004 that "in Bahrain, the Al-Montazah supermarket chain [...] boosted sales by pulling about 1,000 US products off its shelves, and other grocers followed suit." 12 These statements are informative, though they also appear contradictory. Our data and analysis can provide some hard evidence on how consumers behaved during the period in question.

\section{Data}

Our data were kindly provided by Nielsen, the well-known marketing company specializing in consumer goods. We observe prices, sales and distribution of the significant brands in each product category in nine Arab countries (Egypt, Bahrain, Jordan, Kuwait, Lebanon, Oman, Qatar, Saudi Arabia and UAE). The periodicity is monthly for soft drinks and bimonthly for detergents and the period covered varies across countries, as seen in Table 1. Full details of each of the samples used in the analysis are provided in appendix A.

Table 1: Period covered by data for each country and product

\begin{tabular}{|c|c|c|}
\hline Country & Soft Drinks & Detergents \\
\hline Bahrain & Jan. 2002 - Dec. 2005 & Jan/Feb 2002 - Jan/Feb 2005 \\
\hline Egypt & Jan. 2002 - Mar. 2005 & Jan/Feb 2002 - May/Jun 2004 \\
\hline Jordan & Jan. 2002 - Dec. 2005 & Jan/Feb 2002 - Mar/Apr 2005 \\
\hline Kuwait & Jan. 2002 - Dec. 2005 & Jan/Feb 2002 - Jan/Feb 2005 \\
\hline Lebanon & Jan. 2001 - Jun. 2006 & Jan/Feb 2002 - Nov/Dec 2005 \\
\hline Oman & Jan. 2001 - Jul. 2006 & Jan/Feb 2002 - Jan/Feb 2005 \\
\hline Qatar & Jan. 2002 - Dec. 2005 & Jan/Feb 2002 - Jan/Feb 2005 \\
\hline S. Arabia & Jan. 2002 - Jun. 2005 & Jan/Feb 2002 - Nov/Dec 2005 \\
\hline UAE & Jan. 2002 - Dec. 2005 & Jan/Feb 2002 - Jul/Aug 2005 \\
\hline
\end{tabular}

Note: major hostilities in Iraq took place in March-April 2003.

A total of 25 brands of soft drinks appear in our data. ${ }^{13}$ Fourteen of those are US brands

\footnotetext{
12 "Coke and Pepsi battle it out," http://www. ameinfo.com/37492.html, April 8, 2004.

${ }^{13}$ Table 9 in appendix A reports all the brands, together with their country of origin.
} 
distributed by the Coca Cola (CCI) and Pepsi Cola (PCI) corporations. The data include additional categories labeled "Other PCI brands" and "Other CCI brands"; these were dropped from the sample as their sales were trivial. ${ }^{14}$ There is also one major European distributor, Cadbury-Schweppes. The major regional producer is Al-ahram Beverages Company (ABC) which is originally an Egyptian firm that was taken over by Heineken (a European firm) in September 2002. ABC was the state monopoly prior to 1997 but was subsequently privatized. ABC's brands mainly have a presence in Egypt with the exception of Everness, which also sells in Oman, Qatar and the UAE. Table 2 provides summary statistics for soft drinks. Saudi Arabia is by far the biggest market, more than twice as big as second-ranked Egypt. The distribution variable measures the percentage of outlets (weighted by sales) carrying each brand.

Table 2: Summary statistics for soft drinks by country

\begin{tabular}{lrrrrrrrrr}
\hline & \multicolumn{2}{c}{ Quantity } & & \multicolumn{2}{c}{ Price } & & \multicolumn{2}{c}{$\begin{array}{c}\text { Weighted } \\
\text { distribution }\end{array}$} \\
\cline { 2 - 3 } Country & Mean & Std dev. & & Mean & Std dev. & & Mean & Std dev. \\
\hline Bahrain & 69.1 & 120.0 & & 0.66 & 0.32 & & 61.8 & 36.3 \\
Egypt & 571.4 & 801.5 & & 0.54 & 0.29 & & 32.5 & 34.3 \\
Jordan & 220.8 & 354.4 & & 0.71 & 0.43 & & 47.6 & 36.2 \\
Kuwait & 246.8 & 406.3 & & 0.79 & 0.34 & & 65.1 & 34.5 \\
Lebanon & 231.2 & 346.2 & & 0.86 & 0.43 & & 50.3 & 35.7 \\
Oman & 119.1 & 178.1 & & 0.54 & 0.28 & & 69.6 & 38.9 \\
Qatar & 56.9 & 98.1 & & 0.77 & 0.54 & & 62.9 & 39.7 \\
S. Arabia & $1,222.3$ & $1,828.4$ & & 0.74 & 0.37 & & 64.2 & 34.2 \\
UAE & 254.2 & 425.7 & & 0.65 & 0.34 & & 62.1 & 39.2 \\
\hline
\end{tabular}

Note: averages are taken across brands and time-periods. Prices are in nominal US dollars (converted from local currency units at the prevailing exchange rate). Quantities are measured in thousands of $8 \mathrm{oz}$ containers.

A limitation of the dataset is that it lumps sales of all small brands together in an "Others" category and as a result we cannot track the success of individual small brands that were launched to take advantage of the boycott. Mecca Cola appears in our data only in Qatar in

\footnotetext{
${ }^{14}$ Average (across periods and countries) sales of "other CCI brands" were $2808 \mathrm{oz}$ bottles while average sales of other PCI brands were $108 \mathrm{oz}$ bottles. These compare to average sales of CCI's flagship Coca Cola brand of 467 thousand $8 \mathrm{oz}$ bottles.
} 
2003-2005. It also launched in France in November 2002 and in Britain in January 2004. ${ }^{15}$ A second entrant, Arabian Cola, appears in the data only in Oman for the period 2002m8 to 2003m1, during which it records a small total sales volume of 1,500 8-oz bottle equivalents. A third entrant, Qibla Cola, does not appear in the data but was launched in the UK in 2003 and has subsequently entered a number of territories around the world, selling to countries including UK, Netherlands, Norway, Canada, Libya, Pakistan from April 2004 and Malaysia from March $2005 .^{16}$

The fabric detergent market is less concentrated than the soft drinks market and features a number of small local brands and manufacturers. ${ }^{17}$ There are two major American manufacturers, $\mathrm{P} \& \mathrm{G}$ and Colgate. The former is the market leader in almost all the countries in our dataset. Its two main competitors are the European manufacturers Unilever and Henkel. There are also a considerable number of local manufacturers, some of whom operate in more than one country. Another characteristic of our detergents sample is the varying number of brands found in each country. Table 3 provides summary statistics for each country.

\section{Attitudes towards the US}

Survey evidence suggests that attitudes toward the United States in Arab countries worsened in the run-up to and during the Iraq war. Table 4 reports the findings of surveys carried out by Zogby International and the PewResearchCenter during the 2002-2005 period covered by our data. The proportion of people with positive opinions of the US dropped substantially between 2002 and 2004 in five of the six countries (UAE is the exception), but returned to previous levels in most countries in 2005 .

\footnotetext{
15 "Goodbye, Coke. Hello, Mecca Cola," The Washington Post, April 20, 2003.

${ }^{16}$ The company went into receivership in the UK in September 2005. Wikipedia reports that it continues to operate in some countries but we have been unable to confirm this. Records from the Internet Archive (http://www.archive.org) indicate that the company's website (http://www.qibla-cola.com) was live until 2008.

${ }^{17} \mathrm{~A}$ list of all brands in the data is provided in Table 10 in appendix A.
} 
Table 3: Summary statistics for detergents by country

\begin{tabular}{|c|c|c|c|c|c|c|}
\hline \multirow[b]{2}{*}{ Country } & \multicolumn{2}{|c|}{ Quantity } & \multicolumn{2}{|c|}{ Price } & \multicolumn{2}{|c|}{$\begin{array}{c}\text { Weighted } \\
\text { distribution }\end{array}$} \\
\hline & Mean & Std dev. & Mean & Std dev. & Mean & Std dev. \\
\hline Bahrain & 27.4 & 53.7 & 1.69 & 1.16 & 41.4 & 34.1 \\
\hline Egypt & $2,240.3$ & $3,473.2$ & 0.72 & 0.57 & 41.7 & 38.9 \\
\hline Jordan & 182.7 & 320.3 & 1.84 & 1.30 & 42.6 & 34.9 \\
\hline Kuwait & 7.9 & 14.3 & 2.16 & 1.66 & 40.5 & 39.2 \\
\hline Lebanon & 8.4 & 18.8 & 2.15 & 2.48 & 25.5 & 33.6 \\
\hline Oman & 3.9 & 7.9 & 0.35 & 1.23 & 33.6 & 34.9 \\
\hline Qatar & 2.3 & 3.4 & 2.35 & 2.38 & 49.1 & 40.7 \\
\hline S. Arabia & 851.9 & $1,498.3$ & 1.52 & 0.72 & 47.9 & 37.2 \\
\hline UAE & 8.1 & 19.7 & 0.49 & 1.20 & 28.6 & 34.9 \\
\hline
\end{tabular}

Note: averages are taken across brands and time-periods. Prices are in nominal US dollars (converted from local currency units at the prevailing exchange rate). Quantities are measured in thousands of kilograms.

We would like to relate these attitudinal variables to sales of US goods. We specify a simple model of the annual share of US products in a given country as a function of two variables: the natural logarithm of real GDP per capita (INCOME) and the percentage of people in the country with a favorable opinion of the US (FAVORABLE). We assume that the opinions recorded in surveys are representative of the entire year, even though the surveys were conducted over a much shorter period (no more than a month). Doing so gives us observations for two years in five countries. We supplement the Zogby international data with additional survey evidence from the Pew Global Attitudes Project which was conducted in 2003 and 2005 (PewResearchCenter, 2005). The Pew data report the extent of favorable opinion about the US in two of the countries in our study, Jordan and Lebanon. Incorporating this information gives us four more observations on soft drinks and two on detergents (for detergents our sample does not extend to 2005) for a total of 15 and 10 respectively. With these admittedly limited data we estimated the following simple model:

$$
Q_{c t}^{U S} / Q_{c t}^{\text {Total }}=\alpha+\beta \cdot I N C O M E_{c t}+\phi \cdot F A V O R A B L E_{c t}+\varepsilon_{c t} .
$$


Table 4: Opinions of America in the Arab world

\begin{tabular}{lcccccccc}
\hline & \multicolumn{3}{c}{ Zogby } & International & & \multicolumn{5}{c}{ PewResearchCenter } \\
\cline { 2 - 4 } \cline { 7 - 8 } Country & 2002 & 2004 & 2005 & & 2002 & 2003 & 2004 & 2005 \\
\hline Saudi Arabia & 12 & 4 & 9 & & & & \\
Jordan & 34 & 15 & 33 & & 25 & 1 & 5 & 21 \\
Lebanon & 26 & 20 & 32 & & 35 & 27 & & 42 \\
UAE & 11 & 14 & 21 & & & & \\
Egypt & 15 & 2 & 14 & & & & \\
Morocco & 38 & 11 & 34 & & 27 & 27 & \\
\hline
\end{tabular}

Source: Zogby International (2004, 2005) and PewResearchCenter (2005). The numbers reported are the percentages of those surveyed who stated that they hold a favorable view of the US. Our market dataset does not cover Morocco but we included it in the table as it is an Arab country.

The model was estimated using OLS with standard errors computed allowing for correlation among the error terms of observations belonging to the same country. The results are presented in Table 5. Even with only 15 observations, the coefficient $\phi$ is estimated quite precisely (pvalue $=.061)$ and has the expected positive sign in the case of soft drinks. Per capita income is also positive as one might have expected and significant at the $5 \%$ level. The results suggest that a $10 \%$ drop in the percentage of favorable opinions toward the US would lead to a .0258 percentage point drop in the share of US sales in total, which is equivalent to $\$ 43.3$ million of foregone annual revenue. This amount is small, at least when compared to the $\$ 1.7$ billion annual revenue from soft drinks by US corporations in this region. Note that this is only true in the soft drink market. In the case of detergents the coefficient $\phi$ is imprecisely estimated.

The results of this simple exercise are suggestive of a link between public opinion toward the US and sales of soft drinks but not of detergents. We next turn to our main task, which is to explore this possibility in the context of the Iraq war using our unique data on soft drinks and laundry detergents. 
Table 5: Estimates of equation (1).

\begin{tabular}{lcccc}
\hline & \multicolumn{2}{c}{ Soft drinks } & \multicolumn{2}{c}{ Detergents } \\
\hline INCOME & $.023^{*}$ & $(.009)$ & $.128^{\dagger}$ & $(.055)$ \\
FAVORABLE & $.258^{\dagger}$ & $(.125)$ & .457 & $(.354)$ \\
INTERCEPT & $.870^{*}$ & $(.027)$ & .206 & $(.130)$ \\
$R^{2}$ & .288 & & .238 \\
$\mathrm{~N}$ & \multicolumn{2}{c}{15} & \multicolumn{2}{c}{10} \\
\hline${ }^{*} p<0.05,{ }^{\dagger} p<0.10$. Standard errors are in parentheses.
\end{tabular}

\section{$5 \quad$ Descriptive analysis}

We start by presenting descriptive and graphical evidence on the impact of the Iraq war on sales of US soft drinks and detergents in the nine Arab countries in our data. Major combat operations in Iraq began on March 20th 2003 and President Bush declared the end of major combat operations on May 1st 2003. If there was an impact on sales of US products, we would expect it to show up in annual sales figures for the year 2003. Table 6 reports growth rates of sales of US and non-US products in each country over several different periods. Annual sales of US products declined in 2003 relative to the previous year in five of the nine countries in our sample. On the other hand, sales of non-US products increased in all nine countries. In 2003, the (unweighted) average growth over all countries was $2.1 \%$ for US products and $23.3 \%$ for non-US products. By contrast, in 2004 and 2005 the sales growth of US products was somewhat higher than that of non-US products in almost all countries. Note however that the 2004 growth rates are relative to the low sales levels of 2003. During the two-year period 2002-2004, sales of non-US products grew much faster than those of US products in seven out of nine countries, the exceptions being Bahrain and Egypt. The overall picture emerging from Table 6 is that sales of US products were negatively impacted in 2003 but returned to more "normal" growth rates in 2004. We cannot of course say from this table alone whether sales eventually return to the 
levels they would have attained in the counterfactual world of no war.

Table 6: Sales growth rates of soft drinks

\begin{tabular}{|c|c|c|c|c|c|}
\hline & \multicolumn{5}{|c|}{ Growth rates in annual sales between: } \\
\hline & $2002-2003$ & $2003-2004$ & $2004-2005$ & $2002-2004$ & $2002-2005$ \\
\hline \multicolumn{6}{|c|}{ US products } \\
\hline Bahrain & -7.9 & 15.3 & 7.2 & 6.2 & 13.9 \\
\hline Egypt & 10.9 & 4.0 & & 15.3 & \\
\hline Jordan & -8.1 & 20.3 & 23.2 & 10.6 & 36.2 \\
\hline Kuwait & 19.7 & 6.6 & 18.8 & 27.5 & 51.6 \\
\hline Lebanon & 0.8 & 4.6 & -0.5 & 5.5 & 5.0 \\
\hline Oman & -5.3 & 15.0 & 7.6 & 8.9 & 17.1 \\
\hline Qatar & 12.1 & 26.1 & 29.8 & 41.4 & 83.6 \\
\hline S. Arabia & -2.2 & 7.4 & & 5.0 & \\
\hline UAE & -1.6 & 25.6 & 6.0 & 23.6 & 31.1 \\
\hline Mean & 2.1 & 13.9 & 13.2 & 16.0 & 34.1 \\
\hline \multicolumn{6}{|c|}{ Non-US products } \\
\hline Bahrain & 6.0 & -3.8 & 6.6 & 1.9 & 8.7 \\
\hline Egypt & 11.0 & -4.3 & & 6.2 & \\
\hline Jordan & 62.8 & 32.6 & 18.0 & 115.9 & 154.9 \\
\hline Kuwait & 43.1 & 14.2 & 15.3 & 63.4 & 88.3 \\
\hline Lebanon & 12.1 & 5.7 & 1.7 & 18.5 & 20.5 \\
\hline Oman & 16.3 & 13.2 & 2.7 & 31.6 & 35.2 \\
\hline Qatar & 37.7 & 33.5 & 19.1 & 83.9 & 119.0 \\
\hline S. Arabia & 11.4 & 2.7 & & 14.3 & \\
\hline UAE & 9.3 & 27.1 & -3.1 & 38.9 & 34.6 \\
\hline Mean & 23.3 & 13.4 & 8.6 & 41.6 & 65.9 \\
\hline
\end{tabular}

For a more detailed look at the temporal evolution of sales we turn to a graphical depiction of the data. Figure 1 plots 12-month growth rates of monthly sales of US and non-US soft drink products; that is, it compares sales in each month to sales of the same month the previous year. This is different from the growth rates reported in Table 6 , which measure the growth of annual sales. Focusing on monthly 12-month growth rates means that we are able to make a comparison between the same month in different years, the simplest and most transparent way to control for seasonality. The vertical line on each plot marks the beginning of hostilities in Iraq (March 2003). It can be seen that the sales growth rate of US products at the time of the war 


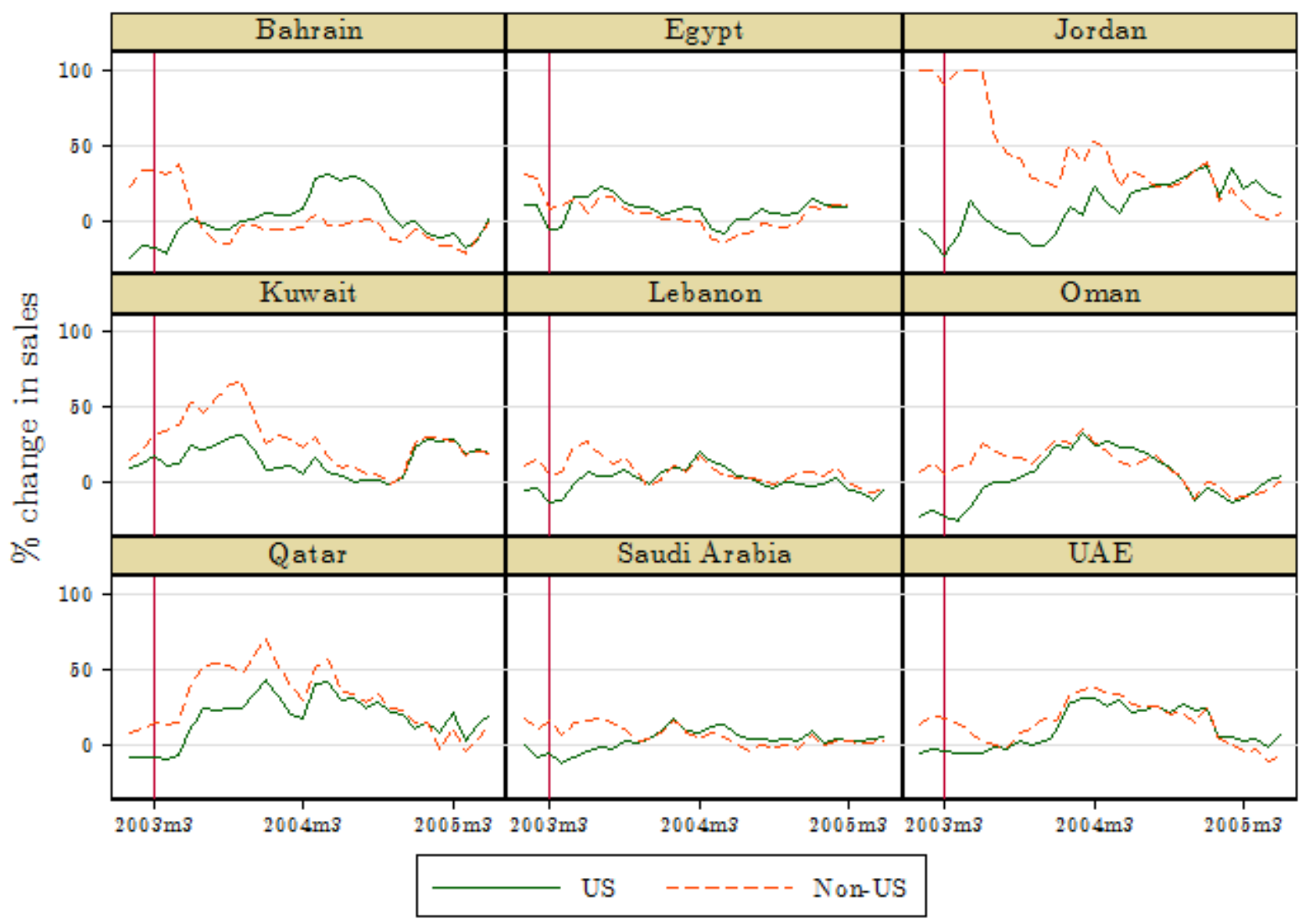

Figure 1: Percentage change in sales of US and non-US soft drinks in each month compared to the same month the previous year. In the case of Jordan percentage changes exceeding $100 \%$ were marked as $100 \%$ in order to keep the scale meaningful. The vertical line denotes the start of hostilities in Iraq.

is slower than that of non-US products in every single country and is in fact negative in all but one of them. The exception is Kuwait, where sales of US products grow consistently throughout 2002-03. Sales of US soft drinks begin showing positive growth rates in almost all countries sometime in the post-war period. Comparing the sales growth of US and non-US products, there is generally a divergence in the rate of growth during hostilities followed by a gradual convergence in the post-war period. Overall, we see Figure 1 as providing strong evidence that the war had a negative impact on US sales and a positive impact on non-US sales. Notice also that US products do not generally appear to experience a clear "catch-up" period wherein their 
Table 7: Sales growth rates of detergents

\begin{tabular}{|c|c|c|c|c|c|}
\hline & \multicolumn{5}{|c|}{ Growth rates in annual sales between: } \\
\hline & $2002-2003$ & $2003-2004$ & $2004-2005$ & $2002-2004$ & $2002-2005$ \\
\hline \multicolumn{6}{|l|}{ US products } \\
\hline Bahrain & 3.5 & 10.4 & & 14.3 & \\
\hline Egypt & 4.4 & & & & \\
\hline Jordan & 2.4 & 9.3 & & 11.9 & \\
\hline Kuwait & -0.9 & 2.6 & & 1.7 & \\
\hline Lebanon & 18.2 & -3.8 & 7.0 & 13.7 & 21.7 \\
\hline Oman & 19.2 & 8.0 & & 28.7 & \\
\hline Qatar & 0.4 & -2.6 & & -2.3 & \\
\hline Saudi Arabia & 8.6 & 14.3 & 7.2 & 24.1 & 33.0 \\
\hline UAE & 8.5 & 6.6 & & 15.7 & \\
\hline Mean & 7.1 & 5.6 & 7.1 & 13.5 & 27.4 \\
\hline \multicolumn{6}{|c|}{ Non-US products } \\
\hline Bahrain & -4.4 & -7.7 & & -11.8 & \\
\hline Egypt & 6.6 & & & & \\
\hline Jordan & -3.5 & -2.8 & & -6.2 & \\
\hline Kuwait & 21.7 & 1.6 & & 23.7 & \\
\hline Lebanon & 14.1 & -1.9 & 0.6 & 11.9 & 12.6 \\
\hline Oman & -6.3 & -5.7 & & -11.6 & \\
\hline Qatar & 5.5 & 1.5 & & 7.1 & \\
\hline Saudi Arabia & 13.6 & -1.0 & -6.3 & 12.5 & 5.4 \\
\hline UAE & 11.5 & -5.7 & & 5.1 & \\
\hline Mean & 6.5 & -2.7 & -2.8 & 3.8 & 9.0 \\
\hline
\end{tabular}

growth rates are higher than their non-US counterparts after the period of lower growth, except perhaps in Bahrain where US growth rates are persistently above the growth rates of non-US products for much of 2004. That is, in the Bahrain graph the dotted line is above the solid line during 2003 and then vice-versa for much of $2004 .^{18}$

\footnotetext{
${ }^{18}$ The attentive reader will have noticed that the time period depicted in Figure 1 starts in January 2003, just three months before the beginning of hostilities. This is because we look at the annual and 12-month growth rates - we have only a limited sample before the beginning of hostilities. However, it is important to note that these are growth-rates so that in fact they are reporting more than a year of data before the "event" we study. In the econometric analysis below we work with levels rather than growth rates so that there is a substantial amount of data before the event being studied. This proves important here, as in many other contexts, as some of the impact we do observe from the boycotts appears to take place in the six month run-up to the war rather than just at the date of the beginning of hostilities.
} 
We repeat the descriptive analysis for the fabric detergent product category. Table 7 reports annual growth rates and paints a very different picture than the case of soft drinks. Growth rates for US products were positive in 2003 in all countries except Kuwait, where it was slightly negative. By contrast, non-US products experienced negative growth in three countries. US products do even better in 2004, when they grow by an average rate of $5.6 \%$ whereas non-US products lose $2.7 \%$ of sales. Between 2002 and 2004, US product sales grow faster in six of the eight countries for which growth rates can be calculated. Overall, there is no evidence of a decline in sales for US products in 2003. The implication is that to sustain a story that the boycott was effective one would have to argue that US products' superior performance in 2004 (relative to non-US products) indicates that sales in 2003 might have grown even faster were it not for the war. Such a position is quite difficult to reconcile with (for example) almost $20 \%$ growth rates in US sales in 2002/03 in Lebanon and Oman.

Figure 2 is the equivalent of Figure 1 for detergent products. It plots growth rates for each two-month period relative to the same period one year earlier ("MA2003" stands for MarchApril 2003). In line with Table 7, we observe that sales of US products grew faster than those of non-US products around the time of the war in four out of the nine countries (Bahrain, Jordan, Lebanon, Oman). Moreover, and again in contrast to the soft-drinks data, in two of the five countries where non-US products grew faster at the time of the war(Saudi Arabia and UAE) there is evidence of a reversal as growth rates of US products overtake those of non-US products a few months after the war and remain higher thereafter. Similarly in Jordan the growth rates of US products drop significantly starting in JF2003 (the first two months of 2003) and start recovering about six months after the war. These patterns differ distinctly from what was observed in the case of soft drinks. In the next section we further investigate these patterns with the tools of formal econometric analysis. 


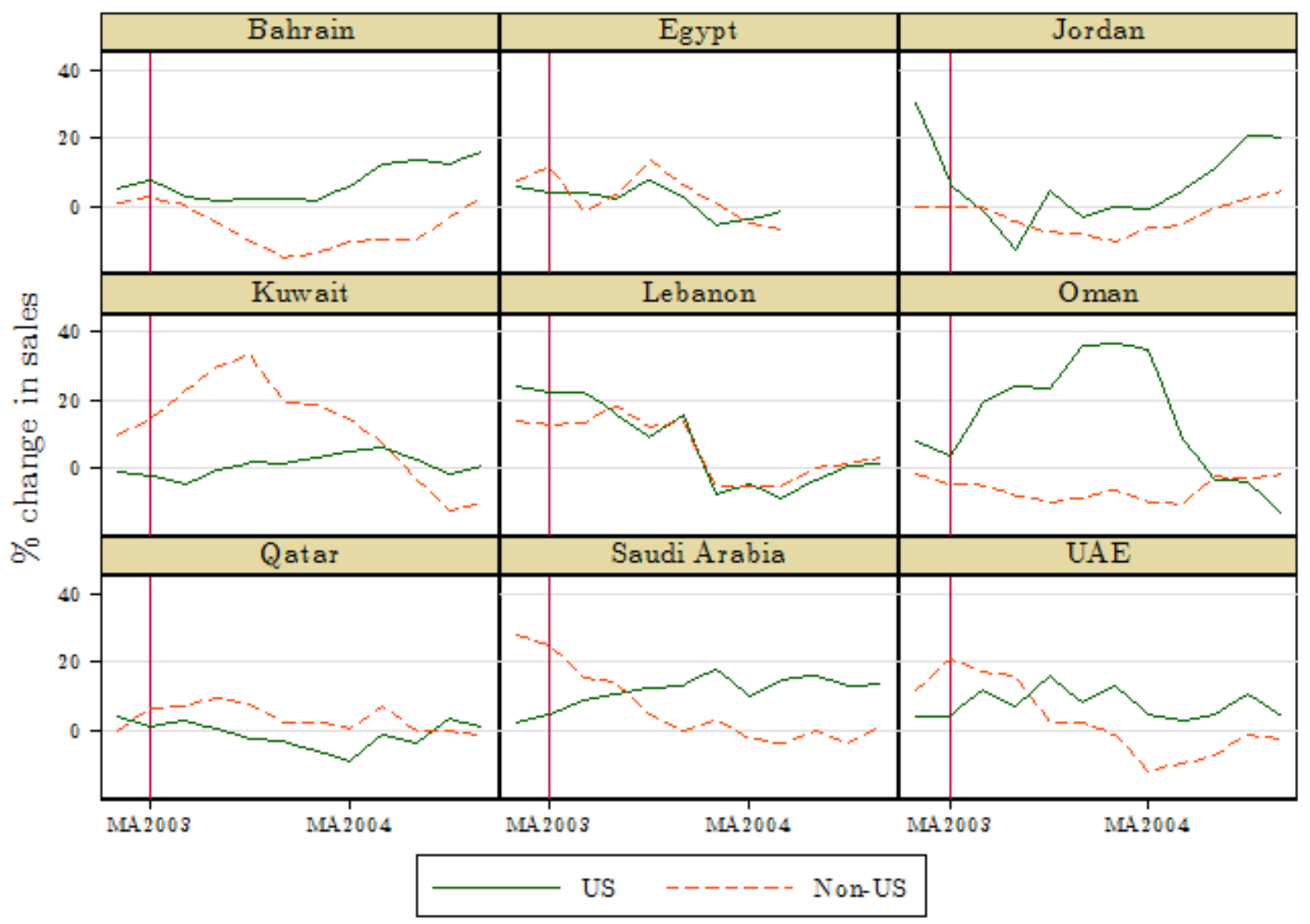

Figure 2: Percentage change in sales of US and non-US fabric detergents in each month compared to the same month the previous year. The vertical line denotes the start of hostilities in Iraq.

\section{Econometric analysis}

A straightforward method for estimating the impact of the war on US sales is to implement a difference-in-difference approach, using non-US sales as the "control" group. We use quotation marks because non-US products are not a control group in the standard sense as their sales may very well be affected, probably in a positive direction, by the treatment (the war). Even so, the data variation is useful to test the hypothesis of a differential effect on the two types of products.

Let $\ln Q_{j c t}$ denote the natural $\log$ of quantity (volume) of sales of brand $j$ at time (month) $t$ 
in country $c$. Let $U S_{j}$ be a dummy variable taking the value of one if product $j$ is a US product and zero otherwise and let $T_{c}$ denote the number of periods we have data for in country $c$. For the baseline econometric model we estimate a log sales difference-in-difference regression:

$$
\ln Q_{j c t}=\alpha_{j c}+\sum_{\tau=2}^{T_{c}} \theta_{c \tau}^{U S} \cdot U S_{j}+\sum_{\tau=2}^{T_{c}} \theta_{c \tau}^{N o n U S} \cdot\left(1-U S_{j}\right)+\varepsilon_{j c t} .
$$

The product-country fixed effect $\alpha_{j c}$ allows the level of sales to vary systematically across brands. The set of parameters $\theta_{c t}^{U S}$ and $\theta_{c t}^{N o n U S}$ for $t=2, \ldots, T_{c}$ are country specific time effects for US products and non-US products respectively. For identification we must fix one US and one non-US time fixed effect in each country, so we set $\theta_{c 1}^{U S}=0$ and $\theta_{c 1}^{N o n U S}=0$ for each $c$.

Notice that this specification decomposes the difference in sales experience for a US product $j$ versus a non-US product $k$ in a given period into three components: (i) a systematic component $\alpha_{j c}-\alpha_{k c} ;$ (ii) an idiosyncratic component $\varepsilon_{j c t}-\varepsilon_{k t c}$; and (iii) a time-specific component $\theta_{c t}^{U S}-$ $\theta_{c t}^{N o n-U S}$. To see this, we can write:

$$
\ln Q_{j c t}-\ln Q_{k c t}=\alpha_{j c}-\alpha_{k c}+\theta_{c t}^{U S}-\theta_{c t}^{N o n-U S}+\varepsilon_{j c t}-\varepsilon_{k c t} .
$$

We focus on the common time-specific component of the difference that coincides with our natural experiment and to do so we want to look primarily at the evolution of the difference $\theta_{c t}^{U S}-\theta_{c t}^{N o n U S}$ over time.

In terms of the level equation, we will examine graphs which plot the time effects $\theta_{c t}^{U S}$ and $\theta_{c t}^{N o n U S}$ for a given country. To fix ideas, Figure 3 shows the kinds of patterns which may emerge, assuming the experiment in the data does have the effects on sales that we are testing for. In each case the time effects are normalized to start at zero, following the identification restriction used in the econometric model. In panels (a), (b) and (c) the treatment is shown to have a differential impact that is short-lived. Panel (b) reflects a degree of market growth over 

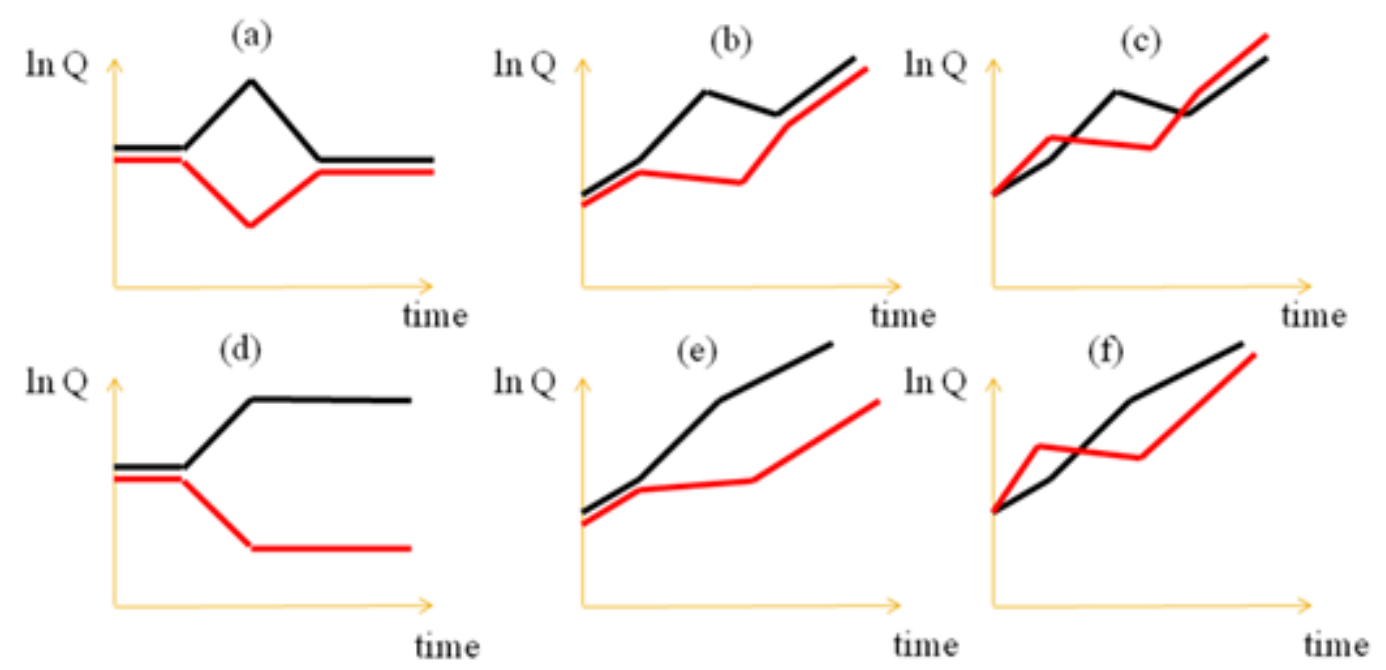

Figure 3: Patterns of differential experience as a result of the experiment. Black lines represent non-US products who may experience a boost in sales while red lines represent adversely effected US products.

time affecting both sets of products equally and panel (c) reflects a faster-trend growth for the adversely affected products. Panels (d), (e) and (f) show longer-lasting effects in contexts that are increasingly complex. In each case the shock associated with the event is seen to emerge at the time of the experiment and then not to go away over time. It is most difficult to see in panel (f) where - as in panel (c) - US products are assumed to have a faster trend growth rate.) In principle, our specification (2) can capture any of the patterns in Figure 3 but identification of differential effects gets more difficult as patterns become more intricate.

The identification strategy we use to examine the differential effect of the war on US and non-US products should have a considerable degree of identifying power against a null hypothesis of no differential effect - the hypothesis associated with an ineffective boycott and of course no change in tastes as a result of the war. Our ability to distinguish between subtler hypotheses will of course be more limited. In particular, we would ideally like to distinguish whether the war has a short or long-run effect. However, establishing the durability of the treatment effect will be harder to determine than its presence for the simple reason that over longer time periods other things may also happen that materially affect sales of both US and non-US products in a 
way we may not be able to control for.

To further see the difficulty consider that the situations envisioned in pictures (c) and (f) are different but may nonetheless be difficult to tell apart empirically. If significant factors (in addition to the war) affect the dynamics of sales volumes during the later period of the experiment then we may struggle to distinguish between short and longer run impacts. For example, suppose the costs of US products increased significantly more than the costs of nonUS products during the later periods in the sample. Then, US products may appear to have a poor sales experience relative to their non-US counterparts over the whole post-experiment life of the sample - even if the effect of the war is, in truth, short-lived. Fortunately, the causes of such effects are quite difficult to dream up in this context since the major costs of producing US and non-US soft drinks are similar (water, sugar, flavoring). To help untangle such effects in addition to examining volume effects we will also examine the effects of the war on pricing and in particular - on access to distribution. If we were to find an important cost or demand driver which had such a differential effect, we would want to include a variable which controlled for the effect in the dummy variable regression thereby producing a "pure" experimental measure in the time effects difference $\theta_{c t}^{U S}-\theta_{c t}^{N o n U S}$.

In this formulation of the regression equation, the fact that we do not pool the data across countries means that all the parameters are country specific and our estimates only use within country data variation. Hence for a given country the presence of brand (country) fixed effects means that the estimates are "within brand" in the sense that they allow for brand specific fixed effects. The estimates use variation across brands and time (within country) to identify $\theta_{c t}^{U S}$ and $\theta_{c t}^{N o n U S}$. The country-time fixed effects control for shocks that might affect sales of all products within each product category in the same way, such as seasonality in demand (demand for soft drinks tends to be higher during the summer months).

The specification in equation (2) aims to capture the difference between sales growth rates for US and non-US products like those reported in Tables 6 and 7 and displayed in Figures 1 and 2 . 
There are, however, some differences between the tables, the figures and the econometrics. The tables report changes in annual sales while the figures use 12-month growth rates. The latter are better suited for capturing short-term effects. In contrast, the econometrics use levels of brand specific monthly sales so that, for example, $100 * \theta_{c t}^{U S}$ tells us approximately the percentage change in an average US brand's sales that have occurred relative to the baseline period zero, wherein we normalize $\theta_{c 1}^{U S}=0$. Also, the tables and figures report changes in aggregate (over brands) sales of US and non-US products, while the econometrics capture the average impact on US versus non-US brands. This average may of course mask a differential impact across brands.

The baseline method of estimating the parameters in our equation is to use OLS. However, our data are likely to exhibit heteroskedasticity: higher sales will likely be associated with a higher variance of the error term. Formal testing confirms this to be the case. Heteroskedasticity does not affect the consistency of the OLS estimators, but it does affect the consistency of our estimated standard errors. A standard remedy for this problem is to estimate equation (2) using weighted least squares (WLS), which weighs each observation according to the value of some independent variable. However, our specification does not have a continuous explanatory variable that could be used as a weighting variable. To circumvent the difficulty, we follow the two-stage procedure suggested by Sen and Srivastava (1990). Specifically, we first estimate equation (2) using OLS and obtain the predicted value of the dependent variable, $\hat{y}$. In the second stage the equation is estimated using $\hat{y}$ (which is a function only of the included explanatory variables) as the weighting variable. Our qualitative results are not sensitive to the use of weighting, but it is in particular appropriate for obtaining consistent estimates of standard errors. The number of observations per country and type of product is provided in Table 8 .

The results of the estimation are best presented in graphical form. In Figure 4 we plot the US and Non-US time fixed effects obtained from estimating equation 2 using WLS. The solid line represents the time fixed effects for US products and the dashed line represents the time fixed effects for non-US products. January 2002 is normalized to zero, hence each point on 
Table 8: Observations used in the econometric analysis

\begin{tabular}{lrr}
\hline Country & Soft Drinks & Detergents \\
\hline Bahrain & 555 & 232 \\
Egypt & 740 & 144 \\
Jordan & 465 & 179 \\
Kuwait & 441 & 213 \\
Lebanon & 368 & 303 \\
Oman & 405 & 278 \\
Qatar & 471 & 184 \\
S. Arabia & 486 & 204 \\
UAE & 568 & 310 \\
\hline
\end{tabular}

the graph represents the mean log difference in sales of a group of products (US or non-US) in that period relative to the same group of products in January 2002. The vertical line on each plot marks the beginning of hostilities in Iraq (March 2003). One can easily observe the strong seasonality in soft drinks sales (substantially higher in the summer than in the winter).

In Figure 4 the dashed line (non-US products) is above the solid line (US products) in all nine countries, suggesting that sales of non-US products grew faster than those of US products throughout the region during this period. The $\times$ 's on the horizontal axis mark periods for which the difference between the two coefficients is statistically significant at the 1-\% level. The basic pattern is consistent, although the difference is never statistically significant in Bahrain and Lebanon and almost never in Kuwait. In Egypt the difference is significant in the middle of the time period but the two lines seem to converge towards the end. The remaining five countries can be said to exhibit a common pattern: sales growth diverges in favor of non-US products sometime around the late spring and summer of 2002 and the gap either remains roughly constant or continues to expand throughout the rest of the sample period. In two countries (Oman and Saudi Arabia) sales of US products actually followed a downward trend.

The graphs provide strong evidence that in at least five Arab countries there was a statistically significant divergence in the sales growth paths of US versus non-US products in favor of the latter. Discussion of a possible military intervention in Iraq had already begun in the 


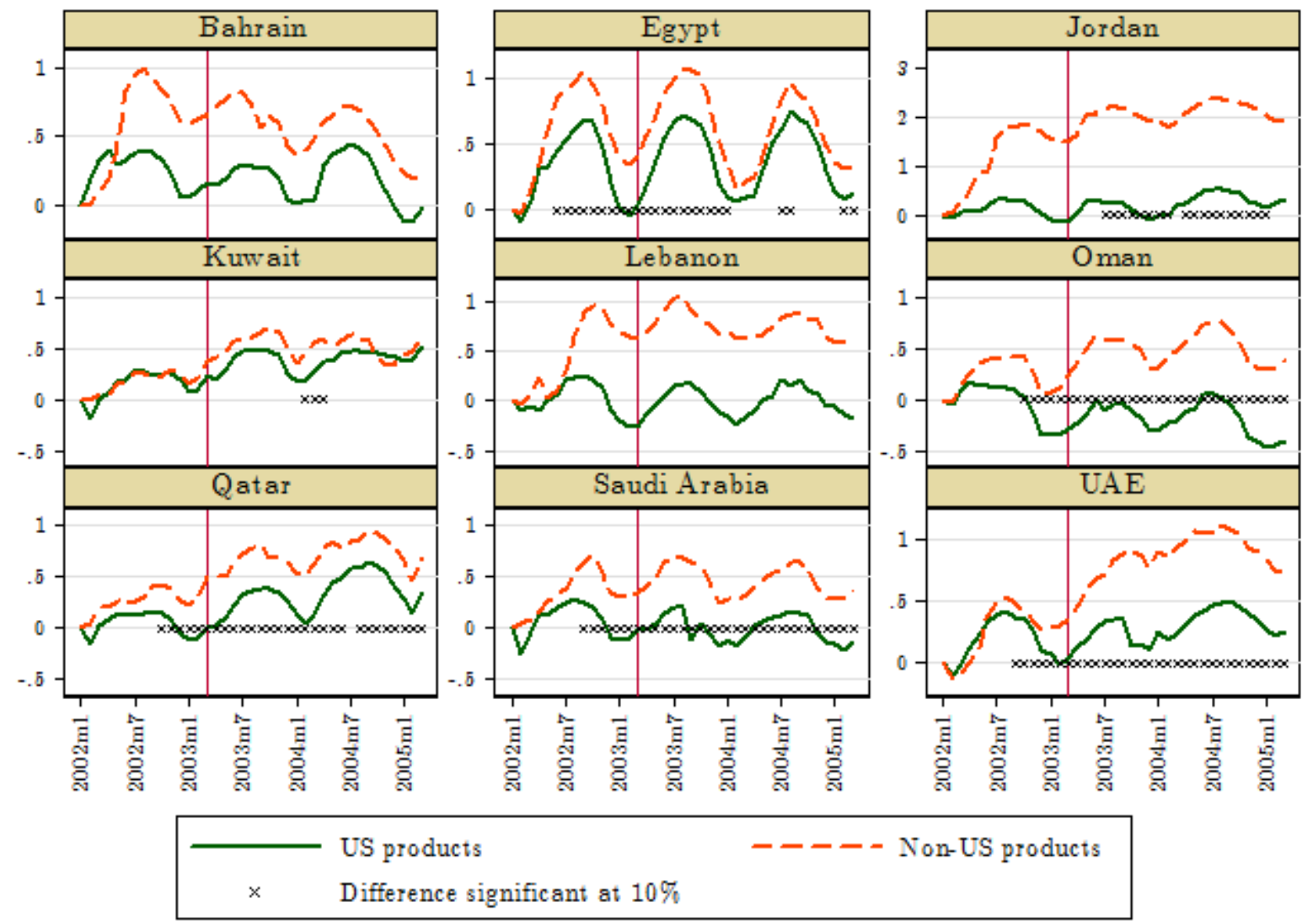

Figure 4: Time effects on sales of soft drinks

summer of 2002. The timing of the divergence coincides with the rise of tensions in the months leading up to actual combat operations and it seems likely that the two are related. Our review of events at the time leading up to the commencement of hostilities has not found another significant event that could explain the differences we are observing. Nonetheless, the fact that the "treatment" period is not clearly defined precludes us from making stronger statements about a causal link between global politics and market outcomes.

If tensions in Iraq led to a negative demand shock for US products, we might expect to see an impact on prices. We test for this by estimating equation (2) using log price as the outcome variable. The estimates are plotted in Figure 5. Statistically significant price divergence is 

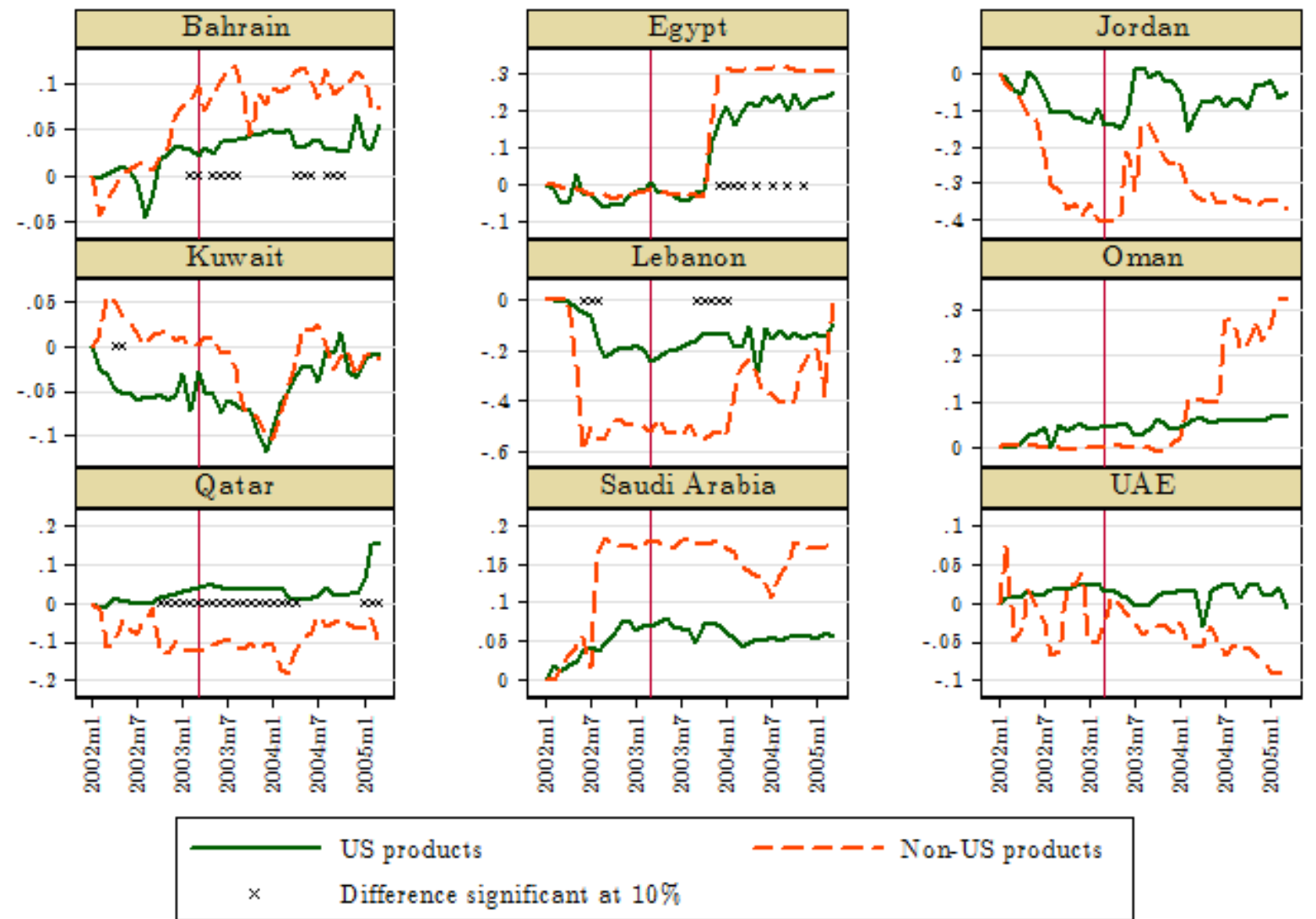

Figure 5: Time effects on prices of soft drinks

observed only in a small number of countries, and there is no clear overall pattern. In some countries there was a relative decline in US prices, while in others we observe the reverse. There is no obvious link between the observed movements in prices and the observed movements in the level of sales. In particular, the price adjustments do not seem to be consistently adjusting to mitigate the impact of the war on US sales. This is not inconsistent with economic theory. It could be, for example, that the elasticity of demand is different across countries.

An important determinant of boycott effectiveness is the extent of retailer participation. If retailers withdraw products from the shelves, then the impact on sales might be expected to be greater. Our dataset reports each product's distribution, that is the sales-weighted number of 


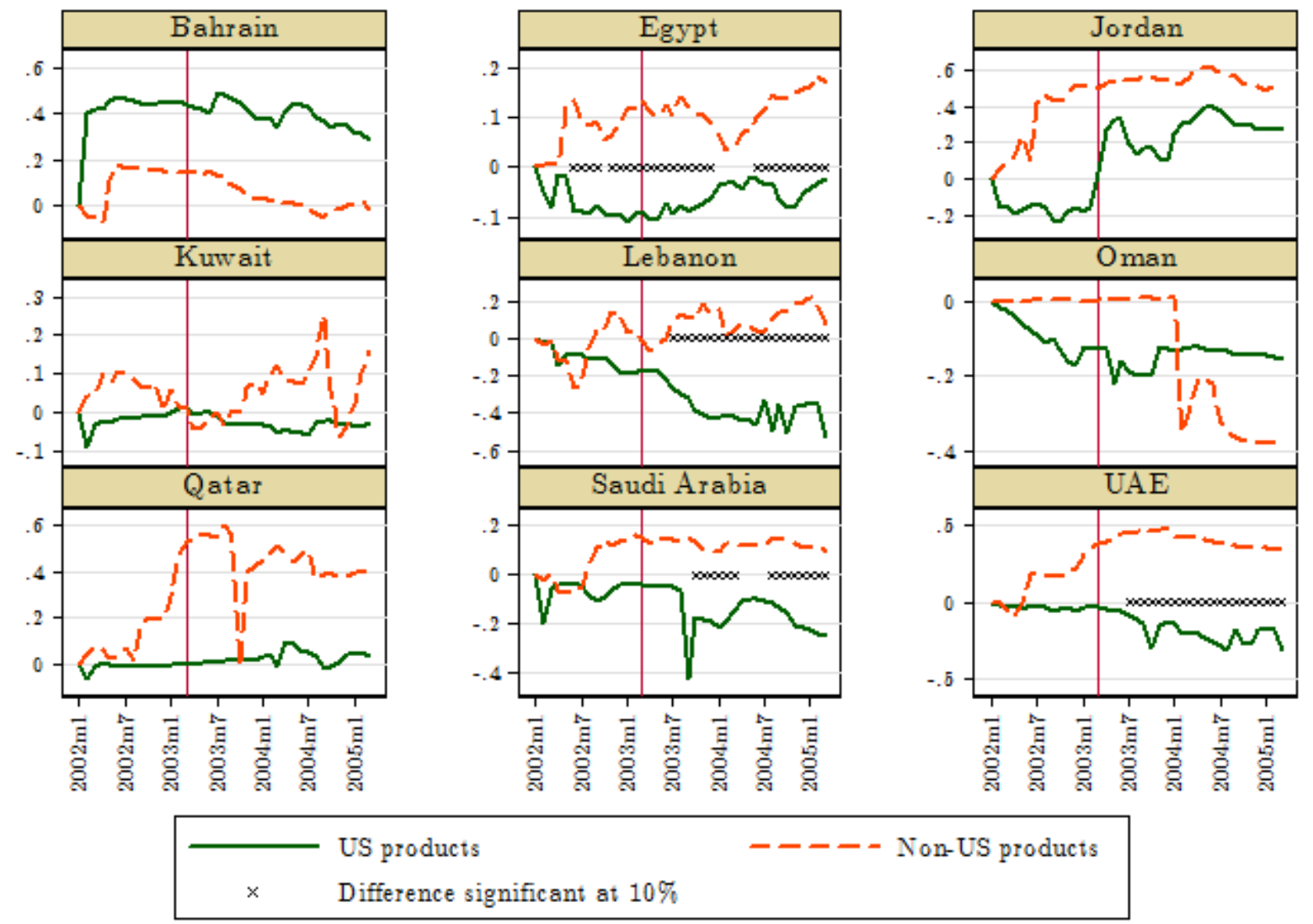

Figure 6: Time effects on distribution of soft drinks

outlets carrying the product. We estimated equation (2) using log distribution as the outcome variable and we present the results in Figure 6. We see a relative improvement in distribution of non-US products in most countries (Bahrain being the only exception). The trends in distribution largely coincide with the trends in sales. It seems that at least part of the relative decline in sales of US products can be attributed to a decline in distribution. It would be interesting to further examine the importance of retailer participation on boycott effectiveness but our data are not rich enough for that.

A second reason to expect apparent price increases would be if relatively low-price stores sold fewer US products during the first half of 2003. If so, then the resulting change in composition 
of selling prices across stores would appear as a positive pricing response. Given this variety of price response, it might be important to add controls for prices in specification (2). We therefore re-estimated equation (2) with the addition of log price as an explanatory variable:

$$
\ln Q_{j c t}=\alpha_{j c}+\ln P_{j c t}+\theta_{c t}^{U S}+\theta_{c t}^{N o n U S}+\varepsilon_{j c t}
$$

Doing so provides an equation that may be thought to represent a demand relationship. However we prefer not to give it this structural interpretation primarily because we do not need to and also because it would be a stretch to claim that we were estimating structural parameters rather than reduced form parameters from this equation. There are at least three reasons for this: (i) changes in observed prices may reflect changes in availability of products at stores with different prices, rather than actual price changes; (ii) generally we would expect the demand for any brand to at least potentially depend on rival brand prices, which are not included in equation (4); and (iii) prices may be correlated with the error term and thus would need to be treated as endogenous variables. ${ }^{19}$ We therefore interpret equation (4) as a reduced-form sales equation that controls for price movements. Estimates from (4) are reported in Figure 8 in appendix B. It seems clear that adding a control for price does not alter the estimates in a significant way.

The econometric analysis was repeated for the case of detergent products. As we argued in the introduction, detergents provide an interesting complement to the soft drink study because in addition to the one large US producer, $\mathrm{P} \& \mathrm{G}$, there are two large European firms, Henkel and Unilever, with a significant presence in each of the countries in our study. In addition there are a number of smaller but still sizable other firms. A campaign to boycott US products might reasonably expect to be successful in the detergents category because the cost of switching to

\footnotetext{
${ }^{19}$ That said, as is commonly the case with data from supermarkets where promotions provide a significant amount of the variation in price data, there appears little evidence of endogeneity of prices and we do indeed estimate a relationship between quantity and price that slopes downward.
} 

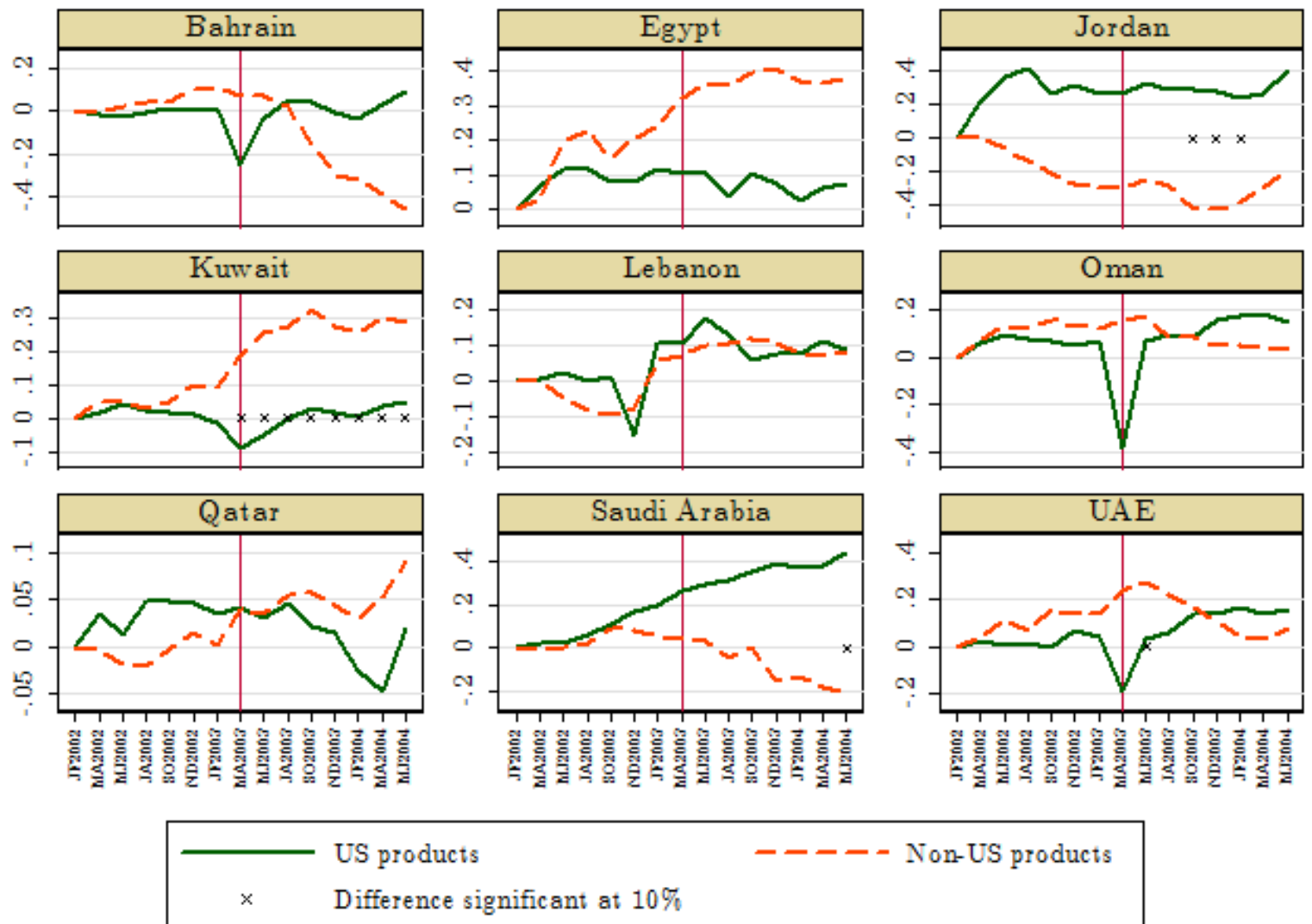

----- Non-US products

Difference significant at $10 \%$

Figure 7: Time effects on sales of detergents

alternative products is likely to be small. ${ }^{20}$

The picture that emerges from the detergent market (Figure 7) is quite different from that of soft drinks. In several countries, US products do better than non-US products. The pattern of divergent sales paths that was observed in almost all countries in the case of soft drinks is only visible in Egypt and Kuwait and is statistically significant only in the latter. In contrast, decidedly short run effects appear in the point estimates in Oman, UAE and Bahrain around the time of combat operations - although these effects are only statistically significant in the UAE. Similarly, the trends in prices and distribution (graphs in appendix B) do not exhibit any

\footnotetext{
${ }^{20}$ On the other hand, it may be hard for others to observe individuals cheating and so informal mechanisms to monitor compliance are harder to use in order to avoid individuals free riding.
} 
consistent patttern that that can be traced to the political climate. We conclude that there is little evidence of more than a short run impact of the war on sales of US detergents, except perhaps in Kuwait. We note that this conclusion is based on fewer data points than in the case of soft drinks (see Table 8).

The results of the econometric analysis largely confirm the descriptive and graphical evidence in the previous section. The Iraq war appears to have had a negative and lasting effect on the sales of some US products, though the impact was by no means universal and its economic magnitude was quite modest. Statistically significant differential effects are picked up in seven countries: Egypt, Jordan, Kuwait Oman, Qatar, Saudi Arabia and the UAE. In the remaining two countries - Bahrain and Lebanon - we observe a differential effect in the same direction but it is not statistically significant. Generally, US soft drink sales exhibit slower sales growth than their non-US competition, but we do not observe a reduction in the level of sales. In the case of detergents the econometric evidence is - just like the descriptive evidence - substantially weaker. We find a statistically significant negative impact on US products in only one country, Kuwait. An interesting aspect of these results is that consumer boycotts emanating from political considerations appear to have been more effective in the market where there are fewer branded alternatives (soft drinks). This is likely to be due to the status of brands such as Coke and Pepsi as iconic American products.

Our estimates are consistent with media reports suggesting that the Iraq war hurt American companies but that the impact was relatively limited. ${ }^{21}$ They are also in line with other recent work showing that international politics can influence consumer behavior. It should be noted, however, that the impact of political events in our study is qualitatively much smaller than the estimates reported in some other studies, ${ }^{22}$ even though one might intuitively have expected the

\footnotetext{
${ }^{21}$ One such report states: "Still, damage from last year's invasion of Iraq could have been worse, says Carline Levy, UBS's beverage analyst in New York. "We thought there would be a big backlash," she says. "It's been less negative than anyone worried," from "Coke and Pepsi battle it out," AMEInfo, April 8, 2004 [http://www . ameinfo.com/37492.html].

${ }^{22}$ See, for example, Michaels and Zhi (2010) and Hong, Hu, Prieger, and Zhu (2011).
} 
effects to be larger given the magnitude of the underlying forces at work.

An instructive contrast can be made with the case of the boycott of Danish products after the publication of cartoons that were considered offensive to Muslims in a Danish newspaper in 2005. The boycott attracted significant retailer participation. From January to early April of 2006 several major retailers withdraw Danish dairy products from their shelves. As a result, sales of these products during that period "came to a standstill". ${ }^{23}$ We found evidence of only a much smaller level of retailer activism in relation to the Iraq war and this might explain the limited impact of boycott campaigns in our case study.

\section{Conclusions}

We leverage Iraq war-induced variation in attitudes towards the United States in Arab countries to investigate whether national sentiment impacts consumer behavior. At a broad level, variation in aggregate market shares of US products across countries correlates with consumer attitudes toward the US in the soft drink market but not in the detergent market. Exploiting our productlevel data, we find a statistically significant negative impact of the war on sales of US products in seven out of the nine countries in our sample in the case of soft drinks but only in one country in the case of detergents. In two countries the impact on soft drinks dissipated quickly but in the remaining five countries it survived throughout our sample, roughly two years after the war.

A likely explanation for the different outcome in the two markets is that soft drink products like Coca-Cola and Pepsi are iconic American products that are closely associated with the US, something that cannot be said of detergent products. We also find evidence that distribution networks may be at least part of the explanation for the different impacts across the two product markets. Overall, our findings suggest that national sentiment does seem to enter some

\footnotetext{
${ }^{23}$ Quote from an executive of the Danish dairy group Arla Foods, reported in "Arla dairy sales crippled by Middle East boycott," Dairy Reporter, January 31, 2006 [http://www.dairyreporter.com/Financial/ Arla-dairy-sales-crippled-by-Middle-East-boycott].
} 
consumers' decision-making process, at least for products that are considered emblematic of a country.

\section{References}

Ashenfelter, O., S. Ciccarella, and H. J. Shatz, 2007, "French Wine and the U.S. Boycott of 2003: Does Politics Really Affect Commerce?," Journal of Wine Economics, 2(1), 55-74.

Baron, D. P., 2001, "Private Politics, Corporate Social Responsibility, and Integrated Strategy," Journal of Economics and Management Strategy, 10(1), 7-45.

— 2003, "Private Politics," Journal of Economics and Management Strategy, 12(1), 31-66.

Chavis, L., and P. Leslie, 2009, "Consumer Boycotts: The Impact of the Iraq War on French Wine Sales in the U.S.," Quantitative Marketing and Economics, 7(1), 37-67.

Fisman, R., and E. Miguel, 2007, "Corruption, Norms, and Legal Enforcement: Evidence from Diplomatic Parking Tickets," Journal of Political Economy, 115, 1020-1048.

Friedman, M., 1999, Consumer Boycotts. Routledge.

Haass, R. N., 1997, "Sanctioning Madness (Political and Economic Sanctions)," Foreign Affairs, $76(6), 74-86$.

Hong, C., W.-M. Hu, J. E. Prieger, and D. Zhu, 2011, "French Automobiles and the Chinese Boycotts of 2008: Politics Really Does Affect Commerce," The B.E. Journal of Economic Analysis 8 Policy (Topics), 11(1), Article 26.

Hufbauer, G. C., K. A. Elliott, T. Cyrus, and E. Winston, 1997, "US Economic Sanctions: Their Impact on Trade, Jobs, and Wages," Working Paper Special. Washington: Institute for International Economics. 
Innes, R., 2006, "A Theory of Consumer Boycotts Under Symmetric Information and Imperfect Competition," Economic Journal, 116, 355-381.

John, A., and J. Klein, 2003, "The Boycott Puzzle: Consumer Motivations for Purchase Sacrifice," Management Science, 49(9), 1196-1209.

Michaels, G., and X. Zhi, 2010, "Freedom Fries," American Economic Journal: Applied Economics, 2(3), 256-281.

PewResearchCenter, 2005, "U.S. Image Up Slightly, But Still Negative: American Character Gets Mixed Reviews," Pew Global Attitudes Project, http://pewglobal.org/reports/ display $\cdot$ php?ReportID $=247$.

Rarick, C. A., 2007, "Economic Sanctions: Failed Foreign Policy Tool and a Cost to American Business," Economic Affairs, 23(3), 65-70.

Sen, A., and M. Srivastava, 1990, Regression Analysis: Theory, Methods and Applications. Springer-Verlag, New York.

Zogby International, 2004, "Impressions of America 2004: How Arabs View America, How Arabs Learn About America," http://aai.3cdn.net/229fc3112466dc002f_wvm6bhed9.pdf.

_ 2005, "Attitudes of Arabs 2005: An In-Depth Look at Social and Political Concerns of Arabs," http://aai.3cdn.net/6e38e45846c8ce7df5_k0m6be9di.pdf. 


\section{APPENDICES}

\section{Appendix A: Data description}

The datasets utilized in the analysis were provided by the retail measurement services division for fast moving consumer goods (FMCG) of the Nielsen company. They refer to the carbonated soft drinks and fabric detergents categories in nine Arab countries: Kingdom of Saudi Arabia (KSA), United Arab Emirates (UAE), Egypt, Lebanon, Jordan, Kuwait, Qatar, Oman and Bahrain. Nielsen employs a stratified national sample of stores in each country in order to collect information for a number of FMGC categories with weekly, monthly or bi-monthly frequency depending on the product category. For the carbonated soft drinks product category information is collected with monthly frequency while for the fabric detergents category the frequency is bimonthly.

The sample size and the statistical precision of estimates in each country are defined based on nationwide retail census information performed by the company and the Nielsen global statistical standards. The sample of stores covers all the channels (store types) through which the product category tracked is moving and stratification takes place at the regional and channel level (double level stratification) splitting the national sample into non-overlapping groups (stratums).

In all countries, for the top end of the trade (Hypermarkets, Supermarkets) as well as for specific channels organized into chains (i.e. Kiosks), the data collection refers to electronic weekly scanning data supplied by the chain stores. In the rest of the channels, data collection is performed through store audits by professional auditors. Primary data collection is performed at the Stock Keeping Unit (SKU) level. Brand level scores and measurements are derived through contemporaneous aggregation of the SKU level data.

The datasets utilized in the analysis include information about all the brands in the market summing up to the total category sales in each case. For each brand considered the available 
data referred to the variables, sales volume (in 1000s 8 oz cases for carbonated soft drinks and kgs for detergents), average weighted price per unit in the local currency of each country, numeric handling distribution and weighted handling distribution. As with the soft drinks data, detergent prices are not comparable across countries because they are denoted in local currencies. The respective brand weighted average prices were derived as a weighted average across all the relevant SKU prices with the sales of each SKU serving as a weight. Numeric handling distribution refers to the percentage number of stores in the country handling any of SKUs belonging to the brand while weighted distribution refers to the percentage sales volume of the category moving through the stores handling each brand.

Table 9: Soft drink brands and number of countries where each is sold

\begin{tabular}{lccr}
\hline Pepsi Cola Intl (USA) & \multicolumn{3}{c}{ Coca Cola Intl (USA) } \\
EVERVESS & 4 & COCA COLA & 9 \\
LIPTON ICE TEA & 7 & CRUSH & 5 \\
MIRINDA & 9 & FANTA & 9 \\
MOUNTAIN DEW & 9 & KREST & 1 \\
PEPSI & 9 & LIMCA & 3 \\
SHANI & 8 & QUWAT JABAL & 5 \\
TEEM & 3 & SPRITE & 9 \\
& & Al-ahram Beverages (Egypt) \\
Cadbury-Schweppes (UK) & 9 & BIRELL & 1 \\
7-UP & CETRINO & 1 \\
CANADA DRY & 1 & FAYROUZ & 1 \\
ROYAL CROWN & 2 & YOUSFINO & 1 \\
SCHWEPPES & 8 & & \\
SPORT COLA & 2 & Ugarit (Syria) & 1 \\
\multicolumn{2}{l}{ Mecca Cola (UAE) } & & UGARIT \\
MECCA COLA & 1 & & \\
\hline
\end{tabular}


Table 10: Detergent brands and number of countries where each is sold

\begin{tabular}{|c|c|c|c|}
\hline \multicolumn{2}{|l|}{ Unilever (UK) } & \multicolumn{2}{|l|}{ National Detergents Co. (Oman) } \\
\hline OMO & 9 & BAHAR & 4 \\
\hline SURF & 8 & NO1 & 3 \\
\hline BONA & 1 & AYAM & 1 \\
\hline SURF & 1 & SUR & 1 \\
\hline CORAL LQD & 5 & PRINO & 1 \\
\hline SUNLIGHT & 5 & SITE & 2 \\
\hline LUX & 5 & & \\
\hline SKIP & 1 & Reckitt Benckiser (UK) & \\
\hline SUPER & 1 & VANISH & 1 \\
\hline RIN & 1 & WOOLITE & 3 \\
\hline WISK & 1 & & \\
\hline ALL & 1 & Colgate (USA) & \\
\hline & & AXION & 1 \\
\hline Henkel (Germany & & GAMA & 1 \\
\hline $\mathrm{DAC}$ & 7 & & \\
\hline PERSIL & 9 & Al Ahilia Detergent Co. (Oman) & \\
\hline DIXAN & 9 & IDEAL & 1 \\
\hline $\mathrm{X}-\mathrm{TRA}$ & 4 & WADI & 1 \\
\hline LE CHAT & 2 & BELLA & 1 \\
\hline WIPP & 1 & SANA & 2 \\
\hline PERWOLL & 1 & & \\
\hline NICE & 1 & Daaboul (Syria) & \\
\hline MIR & 1 & MADAR & 1 \\
\hline PAK & 1 & MOUDHISH & 1 \\
\hline ABAYA & 1 & & \\
\hline CHEK & 1 & Qatar Detergents Company (Qatar & \\
\hline MICOLOR & 1 & PEARL & 1 \\
\hline P\&G (USA) & & ICA (Jordan) & \\
\hline TIDE & 9 & SUPER WHITE & 1 \\
\hline ARIEL & 9 & ORYX & 1 \\
\hline DAZ & 5 & WONDER WHITE & 1 \\
\hline CHEER & 6 & NEON & 1 \\
\hline BONUX & 7 & & \\
\hline LANG & 1 & Ditra-Sitra (UAE) & \\
\hline FAIRY & 4 & TAJ & 2 \\
\hline DASH & 1 & AL NOUJOUOM & 1 \\
\hline YES & 1 & ZAHRA & 2 \\
\hline BOLD & 3 & & \\
\hline FA & 1 & FAX (Turkey) & \\
\hline IVORY & 1 & Evyap & 1 \\
\hline MR. CLEAN & 1 & & \\
\hline
\end{tabular}




\section{Appendix B: Additional figures}
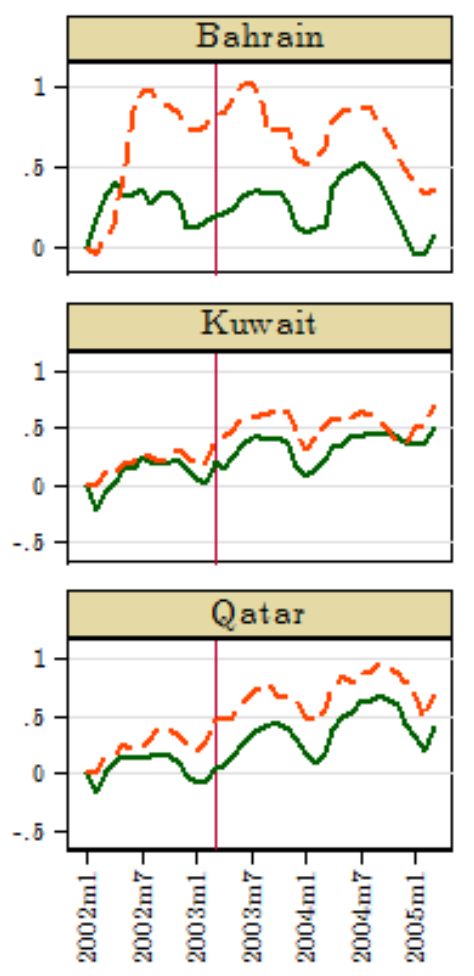
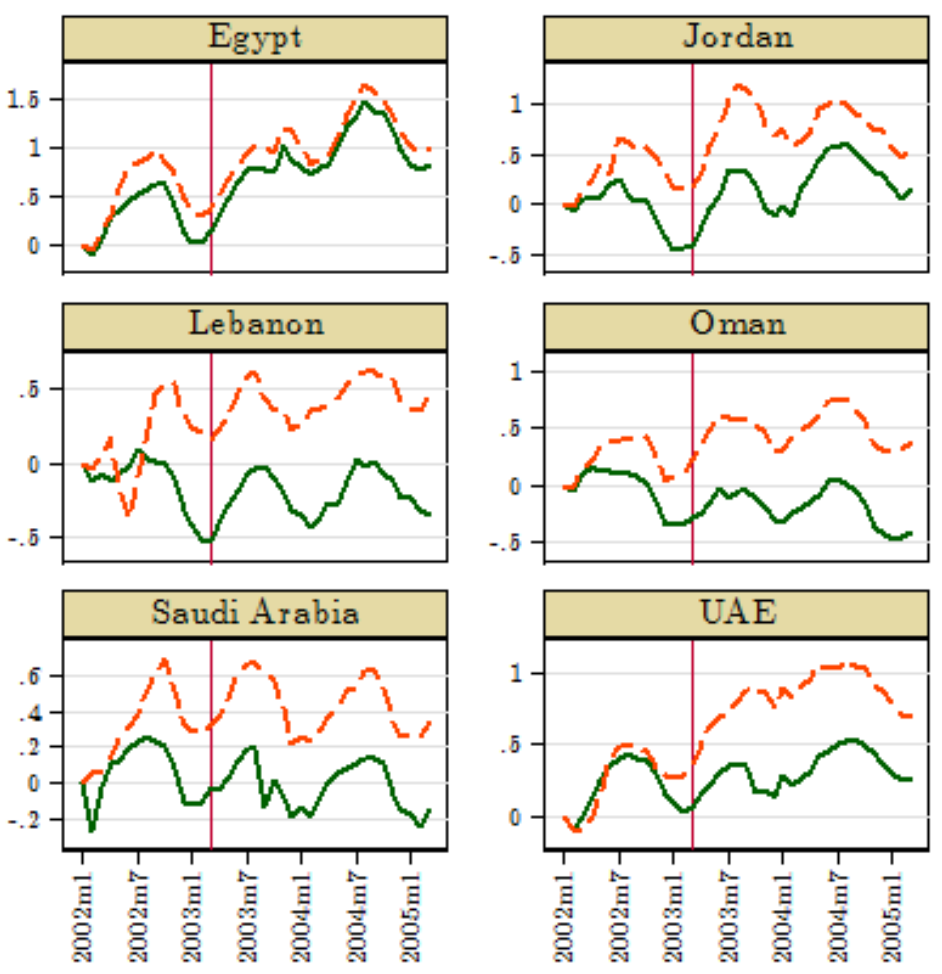

$$
\text { US ----- Non-US }
$$

Figure 8: Time effects on sales of soft drinks, controlling for price 

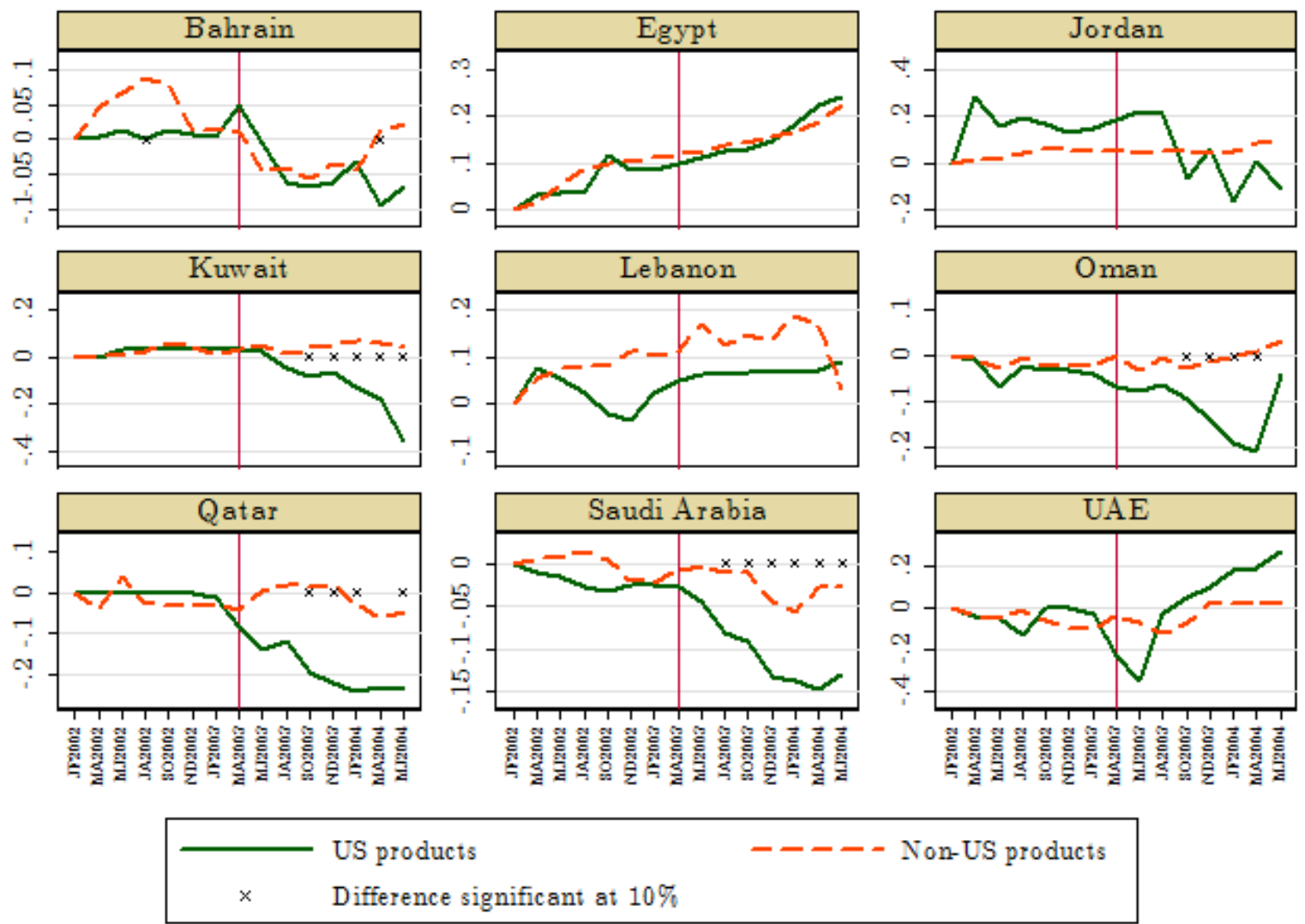

Figure 9: Time effects on prices of detergents 

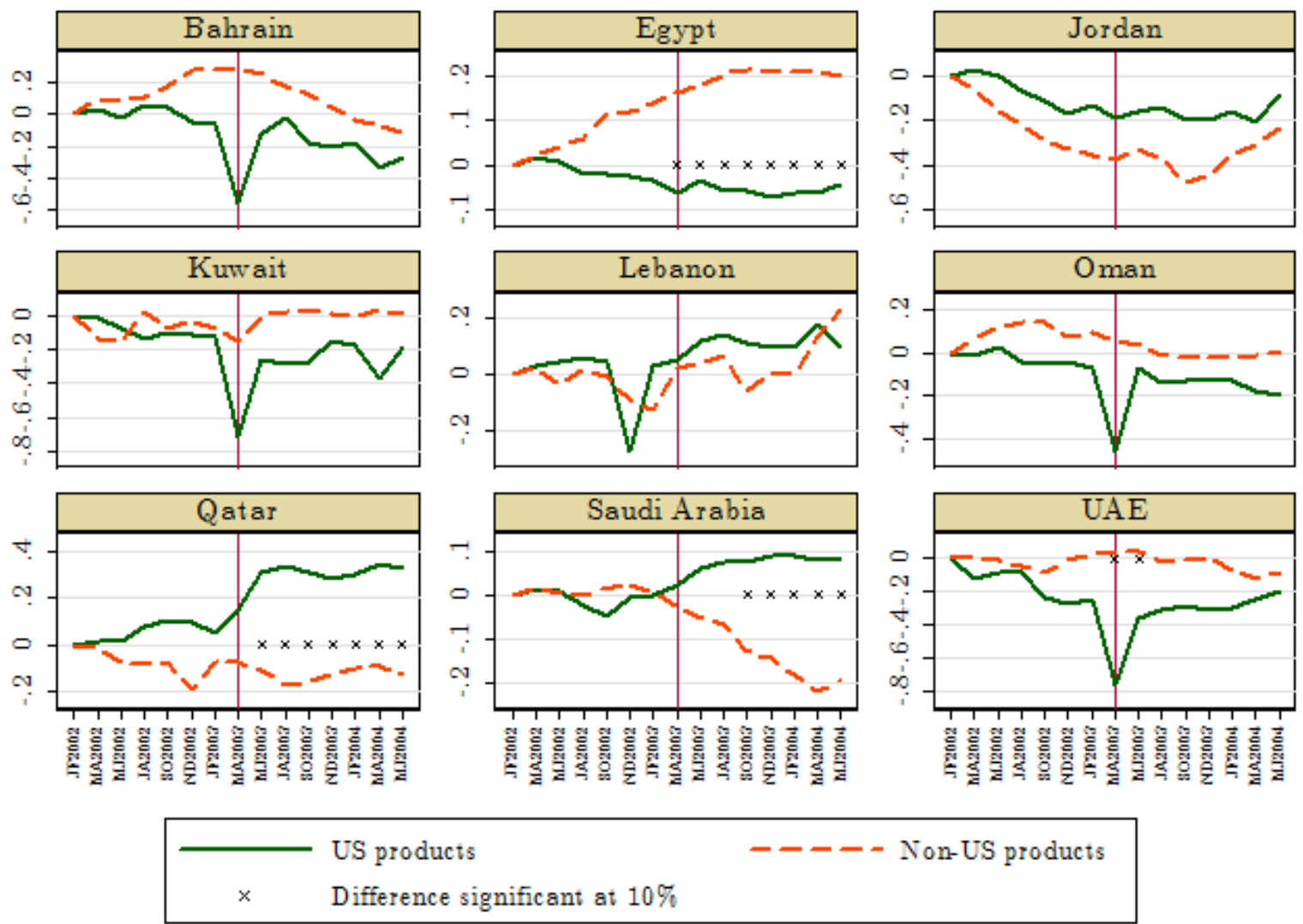

Figure 10: Time effects on distribution of detergents 

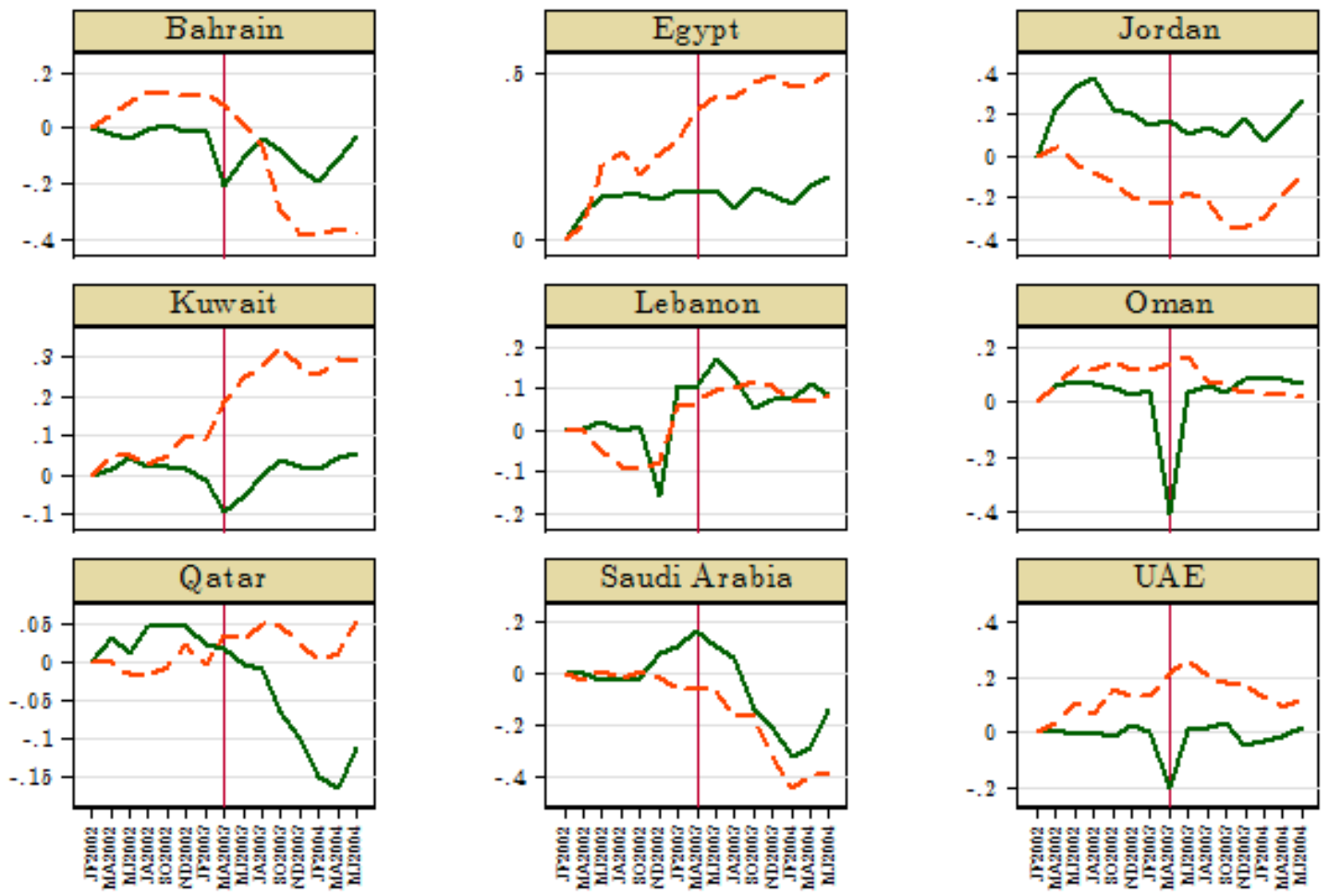

\section{US - - - Non-US}

Figure 11: Time effects on sales of detergents, controlling for price 